\title{
$\beta$-Arrestin2 encourages inflammation-induced epithelial apoptosis through ER stress/PUMA in colitis
}

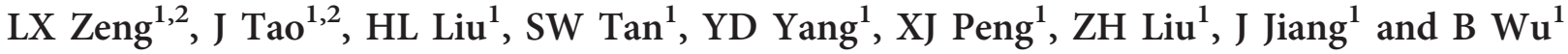

$\beta$-Arrestins ( $\beta$-arrs) are regulators and mediators of $G$ protein-coupled receptor signaling, and accumulating evidence suggests that they are functionally involved in inflammation and autoimmune diseases. However, the effect of $\beta$-arrs is unclear in inflammatory bowel disease (IBD), and the role of $\beta$-arr2 is unknown in ulcerative colitis (UC) and Crohn's disease (CD). The aim of this study is to investigate whether $\beta$-arr2 encourages inflammation-induced epithelial apoptosis through endoplasmic reticulum (ER) stress/p53-upregulated modulator of apoptosis (PUMA) in colitis. In the present study, the results showed that $\beta$-arr2 was increased in specimens from patients with UC or CD. Furthermore, a $\beta$-arr2 deficiency significantly repressed intestinal inflammation, ameliorated colitis, and alleviated mucosal apoptosis in mice. In addition, the targeted deletion of $\beta$-arr2 depressed ER stress, inhibited PUMA, and downregulated PUMAmediated mitochondrial apoptotic signaling in colitis. $\beta$-Arr2, an important modulator of $\mathrm{G}$ protein-coupled receptor function, binds elF2 $\alpha$ to activate ER stress signaling. Furthermore, the knockdown of PUMA dramatically prevented $\beta$-arr2-induced apoptosis via alleviating ER stress in vitro. The results suggest that $\beta$-arr2 encourages inflammationinduced epithelial apoptosis through ER stress/PUMA in colitis and that $\beta$-arr2 is a potential therapeutic target for colitis.

\section{INTRODUCTION}

Inflammatory bowel disease (IBD) comprises a spectrum of chronic and relapsing diseases, including ulcerative colitis (UC) and Crohn's disease (CD). UC is a superficial ulcerative disease affecting the colon that is characterized by the infiltration of inflammatory cells and abnormal cytokine production, leading to mucosal damage and uncontrolled and persistent intestinal inflammation. ${ }^{1}$ UC is intractable to treatment because the mechanism of intestinal mucosal injury is unclear. G proteincoupled receptors (GPCRs), a large superfamily of seven transmembrane cell surface receptors, have enormous potential as new therapeutic targets for drugs used in different diseases, such as the anti-tumor necrosis factor- $\alpha$ (TNF- $\alpha$ ) antibody infliximab, which is clinically used for IBD treatment. ${ }^{2}$ $\beta$-Arrestins ( $\beta$-arr) are scaffolding proteins that regulate GPCR signaling and signal transduction. $\beta$-Arr1 and $\beta$-arr2 are ubiquitously distributed and have a broad role in both GPCRand non-GPCR-related cell signaling. ${ }^{3}$ A recent study indicated that $\beta$-arr1 deficiency protected mice from experimental colitis. ${ }^{4}$ However, the role of $\beta$-arr 2 in colitis remains unknown. $\beta$-arr2 has an important role as a signaling adaptor and scaffold in regulating cellular inflammatory responses. ${ }^{5} \beta$-Arr2 has been suggested to mediate anti-apoptosis signaling pathways and to have a crucial role in the pathogenesis of sepsis and in rheumatoid arthritis models of inflammatory disease. ${ }^{6,7}$ However, researchers have also suggested that $\beta$-arr2 acts as a proapoptosis mediator in airway inflammation and neuropathy. ${ }^{8,9}$ Thus, the anti- or pro-apoptotic effect of $\beta$-arr2 in inflammatory diseases is controversial.

Intestinal epithelial cell (IEC) apoptosis has increasingly been recognized to have a prominent role in UC. Our recent research revealed that IEC apoptosis mediated by p53upregulated modulator of apoptosis (PUMA), a member of the BH3-only Bcl-2 family, contributes to UC and has an essential role in mucosal injury. ${ }^{10}$ In this study, we aimed to further investigate the effect of $\beta$-arr2 on PUMA-mediated IEC

\footnotetext{
${ }^{1}$ Department of Gastroenterology, The Third Affiliated Hospital of Sun Yat-Sen University, Guangzhou, China. Correspondence: B Wu (binwu001@hotmail.com)

${ }^{2}$ These authors contributed equally to this work.
} 
apoptosis in UC. PUMA has been recently linked to endoplasmic reticulum (ER) stress-induced apoptosis. ${ }^{11}$ ER stress has a principal role in colitis and mediates the intestinal mucosal injury and epithelial apoptosis in IBD. ${ }^{12}$ The mitochondrial signaling pathways mediated by PUMA have been linked to ER stress in recent studies, and PUMA appears to be critical for ER stress-induced apoptosis in numerous diseases. ${ }^{13}$ Multiple physiological or pathological conditions can increase ER stress and activate a series of signals that comprise the unfolded protein response (UPR). ${ }^{14}$ The UPR consists of three main signaling arms: inositol requiring enzyme 1, pancreatic ER kinase-like ER kinase (PERK) and activating transcription factor $6{ }^{15,16}$ Prolonged or uncontrolled ER stress can lead to apoptosis. ${ }^{17}$ Following the release of glucose-regulated protein 78 (GRP78), PERK autophosphorylates and phosphorylates eukaryotic initiation factor $2(\mathrm{eIF} 2 \alpha)$, leading to the attenuation of caspase-mediated translation, which regulates genes involved in ER stress-induced apoptosis. ${ }^{18}$ ER protein 72 (ERp72), a member of the protein disulfide isomerase family, like GRP78, is also one of the ER chaperones and is the hallmark of UPR activation. However, the mechanisms of ER stress/PUMA-dependent IEC apoptosis in UC are poorly understood.

In the present study, our data showed that $\beta$-arr2 was upregulated in both UC patients and mouse colitis models, that $\beta$-arr2 bound eIF2 $\alpha$ to activate ER stress signaling and result in PUMA upregulation, and that ER stress/PUMA mediated intestinal epithelial apoptosis through mitochondria-dependent signaling in colitis. The results suggested that $\beta$-arr2 encourages inflammation-induced epithelial apoptosis through ER stress/PUMA in colitis and that $\beta$-arr2 is a potential therapeutic target for colitis.

\section{RESULTS}

\section{$\beta$-arr2 is involved in colitis in both humans and mice}

Our previous study demonstrated that PUMA mediated IEC apoptosis in UC. However, whether $\beta$-arr2 interacts with PUMA in UC remains unclear. We analyzed colitis and uninvolved colonic specimens and matched them with specimens from UC patients without pancolitis. The signs of colonic inflammation were patchy and ranged in severity from lamina propria inflammatory cell infiltrates to crypt abscesses (Figure 1a). Significant apoptosis induction was detected in the superficial epithelium and crypts in the colitis samples, whereas it was limited to the surface epithelium in the uninvolved samples (Figure 1b-d). $\beta$-Arr2 and PUMA expression was increased in 65 and $46 \%$ (17 and 12 out of 26 , respectively) of the colitis samples (data not shown). Protein and mRNA assays confirmed the elevation of PUMA expression in both these UC and CD patients' tissues, and the results indicated that $\beta$-arr2-linked PUMA is involved in human IBD (Figure 1e-f). The protein expression of GRP78 and PUMA was significantly upregulated following $\beta$-arr2 induction (Figure 1e and f). Co-staining of GRP78 and PUMA was observed in the same cells, implying an association between
PUMA and ER stress (Figure 1g). The elevated $\beta$-arr2 expression significantly correlated with the severity of colitis. Furthermore, the induction of apoptosis correlated with $\beta$-arr 2 expression, suggesting that $\beta$-arr 2 might interact with GRP78/PUMA to induce apoptosis in UC.

To further study the role of $\beta$-arr2 in UC, dextran sulfate sodium salt (DSS) was used to induce colitis in mice. ${ }^{19}$ Myeloperoxidase (MPO) activity was clearly increased in the intestinal mucosa (Supplementary Figure S1a online), indicating that the inflammatory response was markedly upregulated. Proinflammatory cytokines, including interleukin (IL) $-1 \alpha$, IL-1 $\beta$, IL- 6 and TNF- $\alpha$, were significantly induced in the colonic mucosa after DSS treatment. However, the colonic mucosal protective cytokines, such as IL-10 and IL-22, were decreased in DSS-treated mice (Supplementary Figure S1b, c). Interestingly, $\beta$-arr $2 \mathrm{mRNA}$ levels increased by fourfold in the DSS-induced intestinal mucosa (Supplementary Figure S1c), and TNF- $\alpha$ significantly induced $\beta$-arr 2 with respect to both mRNA and protein levels (Figure $\mathbf{2 a}$ and $\mathbf{b}$ ). Simultaneously, the expression of GRP78 and PUMA corresponded with $\beta$-arr2 induction in DSS-induced colitis, and immunostaining showed that $\beta$-arr2, GRP78, and PUMA presented highly positive signals in the area of ulceration (Supplementary Figure S1d, e). Thus, $\beta$-arr2 induction in mice colon appears to constitute a rapid response in DSS-induced colitis and the TNF- $\alpha$-induced systemic inflammatory response. The results suggest that $\beta$-arr2 is involved in colitis through its response to inflammation in both humans and mice.

\section{Targeted deletion of $\beta$-arr2 attenuated DSS- and TNBS- induced colitis in mice}

To determine whether the induction of $\beta$-arr2 contributed to colitis, $\beta$-arr 2 knockout (KO) and wild-type (WT) mice were challenged with $5 \%$ DSS. The disease activity index scores ${ }^{20}$ were significantly lower in $\beta$-arr2 KO mice compared with WT mice (Figure 3a). $\beta$-Arr 2 deficiency did not affect the mucosal expression of proinflammatory cytokines IL-1 $\alpha$, IL-1 $\beta$, IL-6, and TNF- $\alpha$ (data not shown), and also did not affect the level of protective cytokines IL-10 and IL-22 in DSS-induced colitis (Supplementary Figure S1c). Mice were submitted to colonoscopy to assess the severity of colitis. Dramatic changes were detected in all DSS-induced mice; they exhibited fragile mucosa with intense hyperemia, edema, and deep and coalescent ulcerations. However, the degree of colitis and the number of ulcers were significantly attenuated, and the mucosal edematous and hemorrhagic erosions were scattered along the entire colon in $\beta$-arr2 $\mathrm{KO}$ mice and WT mice treated with salubrinal, an ER stress inhibitor that inhibits eIF2 $\alpha$ (Figure 3b-d). The histology score $^{21}$ was significantly decreased in $\beta$-arr $2 \mathrm{KO}$ mice and WT mice treated with salubrinal in DSS-induced colitis (Figure $3 \mathbf{e}$ and $\mathbf{f}$ ). In addition, the survival rate and body weight loss of $\beta$-arr $2 \mathrm{WT}$ and $\beta$-arr 2 KO mice was followed after $2 \%$ DSS induction (Supplementary Figure S2a, b). The survival of a cohort of 20 age-matched $\beta$-arr $2 \mathrm{WT}$ and $20 \beta$-arr2 $\mathrm{KO}$ mice exposed continuously to $2 \%$ DSS in the drinking water 14 days was followed. The lethality of 


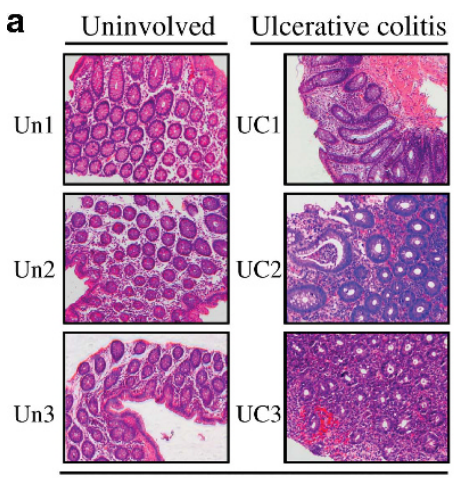

HE staining

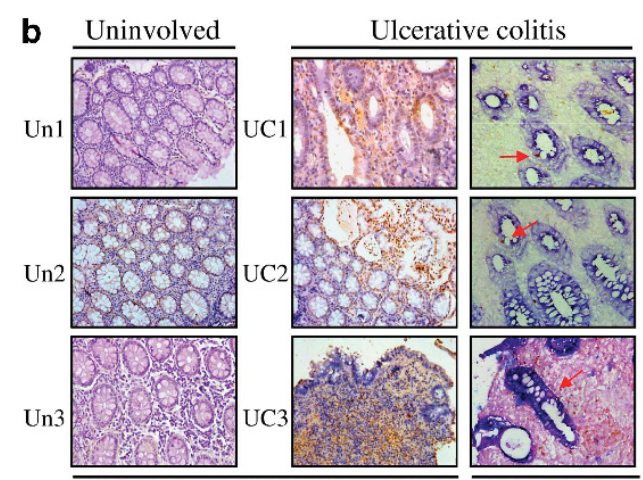

TUNEL(DAB)

TUNEL/CK
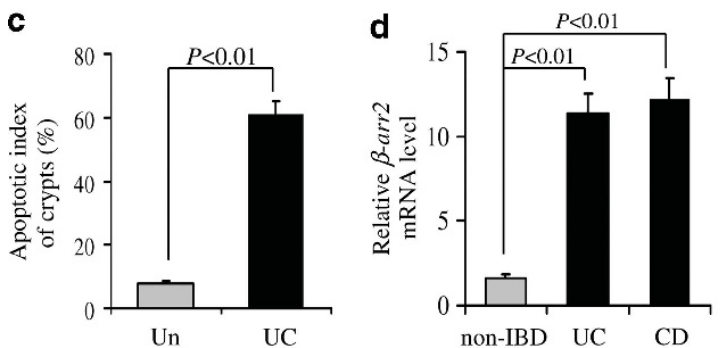

e

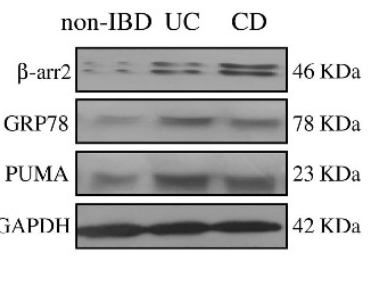

f

UC

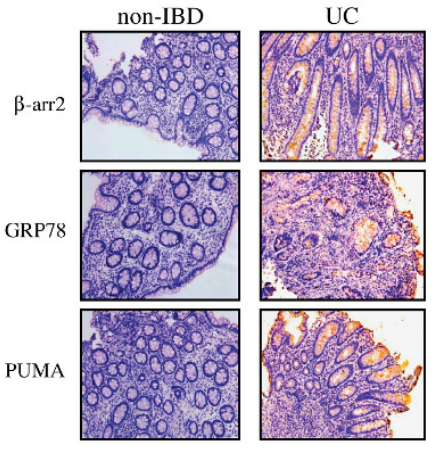

CD

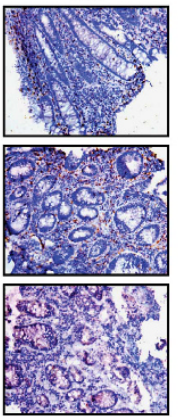

g

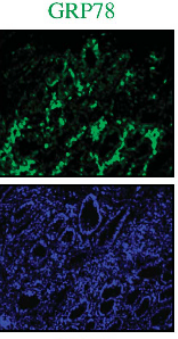

DAPI

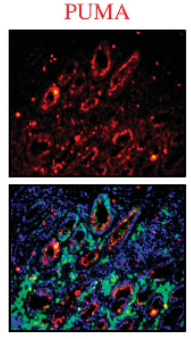

Merge

Figure $1 \beta$-arr2 is involved in human IBD via ER stress/PUMA. (a) hematoxylin and eosin (H\&E) staining of the matched pairs of uninvolved colonic and colitis tissues from three patients with UC (original magnification, $\times 200$ ). (b) Apoptosis in these three matched pairs of uninvolved colonic and colitis tissues was analyzed by TUNEL staining (brown). Double staining with TUNEL (brown) and cytokeratin (blue) confirmed the epithelial cell apoptosis in these patients with UC (original magnification, $\times 200$ ). (c) The apoptotic index was measured by counting the TUNEL signals in 100 randomly selected crypts. The values are expressed as the mean $\pm \mathrm{s}$.d. ( $n=6$ in each group). (d) $\beta$-arr2mRNA expression in colitis tissues from six patients with UC and six patients with CD was analyzed by real-time PCR, and six non-IBD colonic mucosal tissues were used as the control. (e) Increases in $\beta$-arr2, GRP78, and PUMA protein expression in the patients with IBD were analyzed by western blotting, and non-IBD colonic mucosal tissues were used as the control. (f) Immunostaining showed that $\beta$-arr2, GRP78, and PUMA expression (brown) were remarkably increased in colitis tissues from the patients with UC and CD (original magnification, $\times 200$ ). (g) Double staining for PUMA and GRP78 was performed in human UC specimens (original magnification, $\times 200$ ). The nuclei were stained with DAPI in blue. The localization of PUMA was visualized in red and GRP78 was visualized in green. PUMA and GRP78 doublepositive cells were visualized in yellow. CD, Crohn's disease; DAPI, 4',6-diamidino-2-phenylindole; ER, endoplasmic reticulum; GRP78, glucoseregulated protein 78; IBD, inflammatory bowel disease; PUMA, p53-upregulated modulator of apoptosis; TUNEL, terminal deoxynucleotidyl transferase dUTP nick end labeling; UC, ulcerative colitis; $\beta$-arr2, $\beta$-arrestin 2.

$\beta$-arr 2 WT began at 10 days and increased dramatically. After 14 days, $80 \%$ of the $\beta$-arr 2 WT mice but only $10 \%$ of the $\beta$-arr 2 KO mice had died. Dramatic weight loss of $\beta$-arr2 WT mice began at 6 days and significantly accelerated over time, and the weight loss was noticeably slower in $\beta$-arr2 $\mathrm{KO}$ mice. The data suggest that $\beta$-arr2 has an essential role in colitis.

Furthermore, another colitis model that resembles CD was induced by 2,4,6-trinitrobenzenesulfonic acid (TNBS) to evaluate the extensive effect of $\beta$-arr2 in colitis. Similar to the DSS treatment, TNBS treatment also significantly induced $\beta$-arr2 mRNA and protein expression in WT mice (Supplementary Figure S3 a-c). TNBS-induced colitis and colonic damage were substantially relieved in $\beta$-arr2 $\mathrm{KO}$ mice compared with those in WT mice (Supplementary Figure S3d, e). TNBS-induced mucosal apoptosis was also markedly restrained in $\beta$-arr2 KO mice (Supplementary Figure S3d, f). These results confirm that $\beta$-arr2 has a critical role in colitis and mucosal apoptosis.

\section{$\beta$-Arr2 mediated colitis via the induction of epithelial and goblet cell apoptosis in mice}

IEC apoptosis has a pivotal role in the development of UC. ${ }^{22}$ However, the role of intestinal mucosal cell apoptosis in UC is unclear. Intestinal mucosal apoptosis was dramatically induced 
in the ulcerated regions following the infiltration of inflammatory cells, which was blocked by $52 \%$ in the $\beta$-arr $2 \mathrm{KO}$ mice compared with the WT mice (Figure 4a and b). A TUNEL (terminal deoxynucleotidyl transferase dUTP nick end labeling) assay co-stained with cytokeratin and Periodic Acid-Schiff confirmed that the epithelial and goblet cell
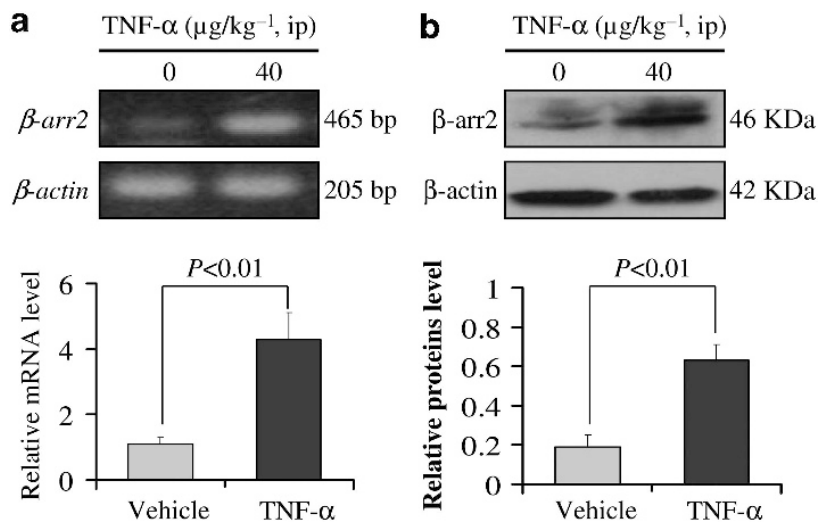

Figure 2 TNF- $\alpha$ induced colonic mucosal $\beta$-arr2 expression in mice. $(\mathbf{a}, \mathbf{b})$ The expression of intestinal mucosal $\beta$-arr2 mRNA and protein was evaluated in TNF- $\alpha$-treated mice using real-time PCR and western blotting. Values in $\mathbf{a}, \mathbf{b}$ are the mean \pm s.d. ( $n=6$ in each group). TNF- $\alpha$, tumor necrosis factor- $\alpha$; $\beta$-arr2, $\beta$-arrestin 2. apoptosis depended on $\beta$-arr2 in the crypt areas. A TUNEL assay co-stained with CD3 showed that lymphocyte apoptosis is rare in colitis (Figure 4c). Similarly, immunofluorescence staining confirmed that caspase-3, a key caspase in the execution of apoptosis, is significantly activated in colitis (Figure 4d-f); however, the targeted deletion of $\beta$-arr2 remarkably downregulated caspase-3 activation (Figure $4 \mathbf{d}-\mathbf{f}$ ). Furthermore, the positive staining of IEC and goblet cells was obviously increased in the $\beta$-arr $2 \mathrm{KO}$ mice compared with the WT mice after DSS induction (Supplementary Figure S4a, b). However, the positive staining of intestinal CD3 and MPO was not distinctly different in either $\beta$-arr $2 \mathrm{KO}$ mice or WT mice after DSS induction (Supplementary Figure S4c, d). To summarize, these results demonstrate that $\beta$-arr2 mediates colitis via the induction of epithelial and goblet cell apoptosis in mice.

\section{Inhibition of TNF- $\alpha$ alleviated mucosal apoptosis by downregulating $\beta$-arr2 in colitis}

A hallmark of severe IBD is the overproduction of TNF- $\alpha$, a proinflammatory mediator, in colonic mucosa. ${ }^{23}$ One GPCR, proteinase-activated receptor- 2 , induces TNF- $\alpha$ production, and the effect is closely related with $\beta$-arr2 in allergic asthma. ${ }^{24}$ However, whether the effect of $\beta$-arr2 is regulated by TNF- $\alpha$ in colitis is unknown. Pretreatment with infliximab, an antiTNF- $\alpha$ antibody clinically used for IBD treatment, significantly a

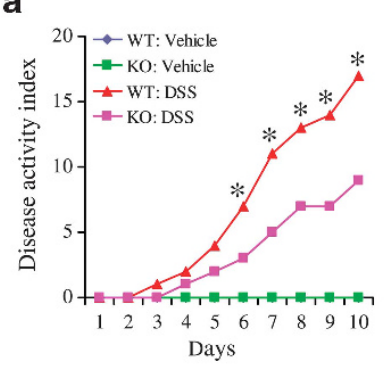

d

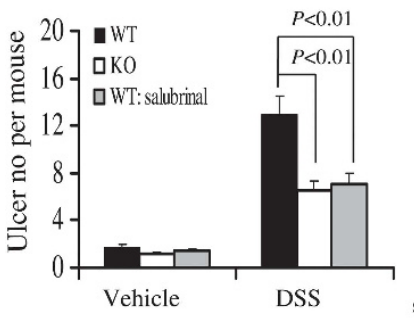

b

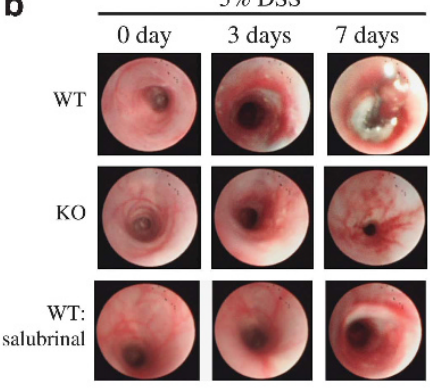

e

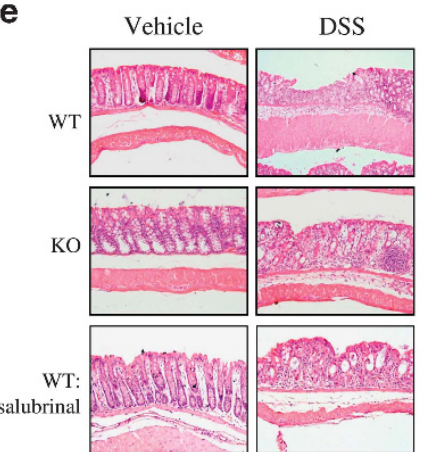

C

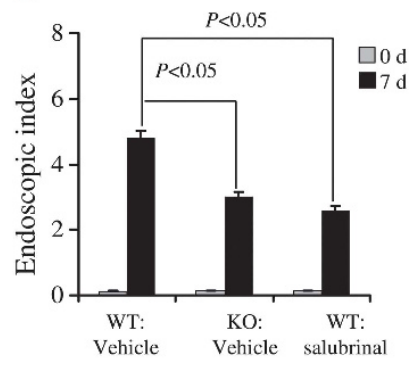

f

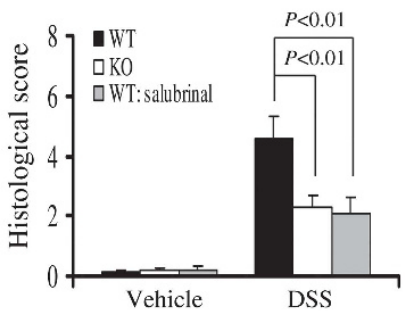

Figure 3 Targeted deletion of $\beta$-arr2 attenuated DSS-induced colitis in mice. $\beta$-Arr2 KO and WT mice were treated with $5 \%$ DSS to induce experimental colitis. (a) The disease activity index was determined at the indicated time points, as described in the Methods. ${ }^{*} P<0.01$ compared with the WT mice. (b, c) Colonoscopic imaging was obtained after colitis induction on days 0,5 , and 7 . Ulcers were alleviated in $\beta$-arr $2 \mathrm{KO}$ mice and salubrinal-treated WT mice. Quantitative analysis of the endoscopic index also diminished in these two groups. (d) Colonic ulcers were reduced in $\beta$-arr2 KO and salubrinaltreated WT mice compared with WT mice after DSS treatment for 7 days. (e) Colonic mucosal damage was observably relieved in $\beta$-arr2 KO and salubrinal-treated WT mice compared with vehicle-treated WT mice after DSS feeding for 7 days (hematoxylin and eosin (H\&E) staining: original magnification, $\times 200$ ). (f) Histological damage after DSS feeding for 7 days was scored after H\&E staining as in $\mathbf{e}$. Values in a, $\mathbf{c}, \mathbf{d}$ and $\mathbf{f}$ are the mean \pm s.d. ( $n=6$ in each group). DSS, dextran sulfate sodium salt; KO, knockout; WT, wild type; $\beta$-arr2, $\beta$-arrestin 2. 
a

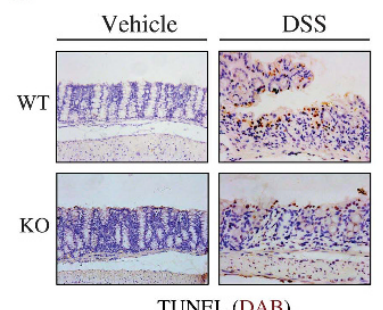

TUNEL (DAB) b

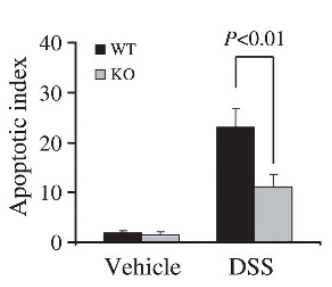

C

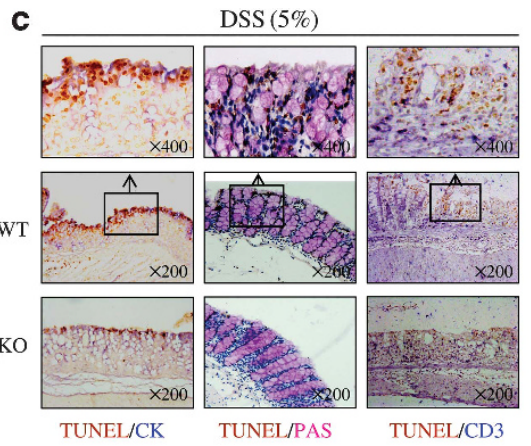

d

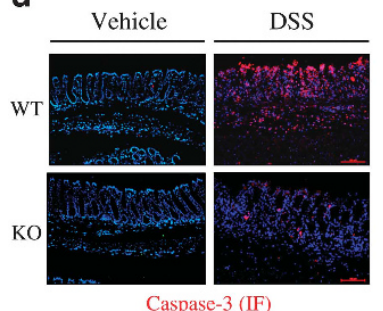

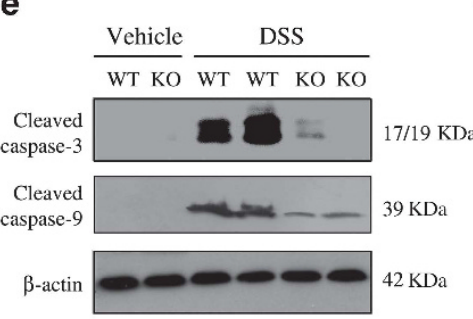

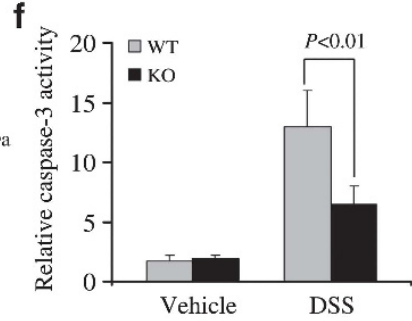

Figure $4 \beta$-Arr2 mediated colitis via the induction of epithelial and goblet cell apoptosis in mice. $\beta$-Arr2 KO and WT mice were subjected to $5 \%$ DSS for 7 days. (a, b) Apoptosis, indicated by TUNEL staining, was suppressed by $\beta$-arr2 deficiency (original magnification, $\times 200$ ). (c) Double staining for TUNEL and cytokeratin (CK) or Periodic Acid-Schiff (PAS) confirmed that apoptosis was attenuated in epithelial and goblet cells, but not in active T lymphocytes stained with CD3, in the $\beta$-arr2 KO mice compared with WT mice. (d) Caspase-3 activity indicated by cleaved caspase-3 immunofluorescence staining was inhibited by the $\beta$-arr2 deficiency. (e) Active caspase- 3 and caspase- 9 expression was probed by western blotting. (f) Active caspase- 3 was quantified by densitometry and the results were normalized to the signals of the loading controls. The values in $\mathbf{b}$ and $\mathbf{f}$ are the mean \pm s.d. ( $n=6$ in each group). DSS, dextran sulfate sodium salt; KO, knockout; TUNEL, terminal deoxynucleotidyl transferase dUTP nick end labeling; WT, wild type; $\beta$-arr2, $\beta$-arrestin 2.

ameliorated colitis by decreasing the disease activity index. In addition, colonoscopy showed that the mucosal edematous and hemorrhagic erosions with ulcers were significantly ameliorated by infliximab pretreatment in the DSS-induced mice (Figure 5a and $\mathbf{b}$ ). A histological evaluation showed that mucosal injury, including injury in the villus and crypts, was markedly mitigated, and the histology score was evidently decreased in DSS-induced mice after infliximab treatment (Figure $\mathbf{5 c}$ and $\mathbf{d}$ ). The TUNEL estimate indicated that intestinal mucosal apoptosis was repressed, and the apoptotic index was significantly reduced in the mice with colitis after infliximab treatment (Figure $\mathbf{5 e}$ and $\mathbf{f}$ ). A western blotting assay showed that treatment with infliximab remarkably limited the expression of $\beta$-arr2 and GRP78 and inhibited the activation of caspase-12, caspase- 9 , and caspase- 3 in DSS-induced colitis (Figure 5g). The results reveal that the inhibition of TNF- $\alpha$ alleviates epithelial apoptosis by downregulating $\beta$-arr 2 in colitis and indicate that $\beta$-arr2 might induce ER stress to contribute to mucosal apoptosis in colitis.

\section{$\beta$-Arr2 mediated mucosal apoptosis by ER stress signaling in colitis}

To confirm whether ER stress was targeted downstream by $\beta$-arr2 in colitis, we used $\beta$-arr $2 \mathrm{KO}$ and WT mice to induce colitis via DSS. Immunohistochemical staining showed that intestinal GRP78 and cleaved caspase-12 expression were significantly increased in the DSS-induced mice; however, the increase was markedly attenuated in the $\beta$-arr $2 \mathrm{KO}$ mice compared with WT mice (Figure 6a and $\mathbf{b}$ ). Western blotting showed that intestinal mucosal p-eIF2 $\alpha$, sXBP1, and ERp72, proximal effectors of UPR signaling, were notably upregulated in the DSS-induced mice, and this upregulation was evidently attenuated by $\beta$-arr2 deficiency (Figure 6c). The data suggested that ER stress is a downstream target of $\beta$-arr 2 in colitis. To determine whether the role of $\beta$-arr2 depends on ER stress signaling in colitis, we induced intestinal $\beta$-arr2 expression by injecting TNF- $\alpha$ intraperitoneally in mice. The results showed that $\beta$-arr2 deficiency significantly suppressed GRP78 expression, eIF $2 \alpha$ phosphorylation, and caspase-12 activation in the intestinal mucosa after TNF- $\alpha$ treatment (Figure 6d). Furthermore, we intraperitoneally administered tunicamycin in mice, which induces ER stress by blocking ER protein glycosylation, to stimulate ER stress. The data indicated that the targeted deletion of $\beta$-arr2 repressed tunicamycin-induced GRP78 expression, eIF2 $\alpha$ phosphorylation, and caspase-12 activation in the intestinal mucosa, resulting in the downregulation of ER stress signaling (Figure 6e). Furthermore, increased $\beta$-arr2 expression could be detected in purified IECs from DSS- and TNBS-treated mice, and GRP78 and cleaved caspase-12 were significantly increased (Figure 6f). Interestingly, PUMA and caspase-3 activation were also remarkably induced in IECs by DSS and TNBS (Figure 6f). The results suggest that $\beta$-arr2 function depends on ER stress signaling in colitis and that PUMA involves in the ER stress signaling. 

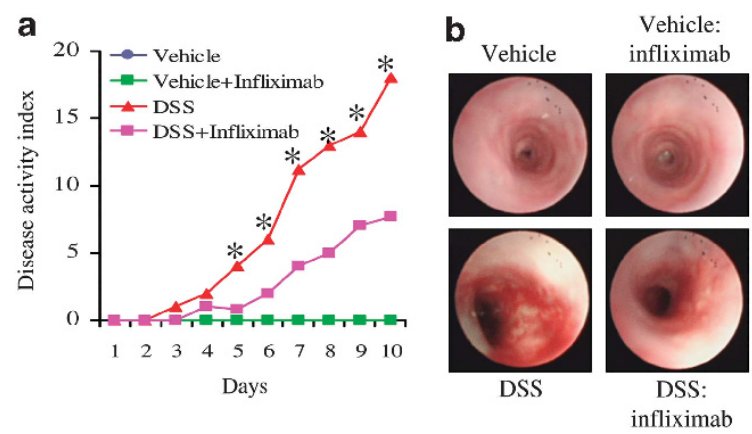

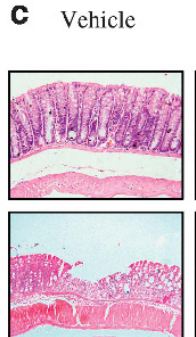

DSS

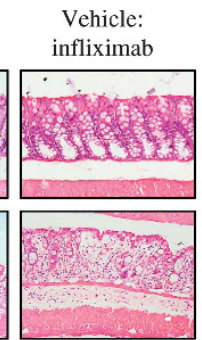

DSS:

infliximab

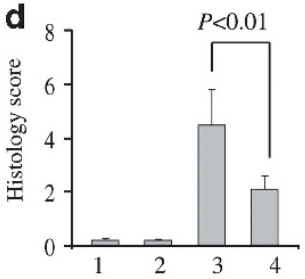

1. Vehicle

2. Vehicle + Infliximab

3. DSS

4. DSS + Infliximab e

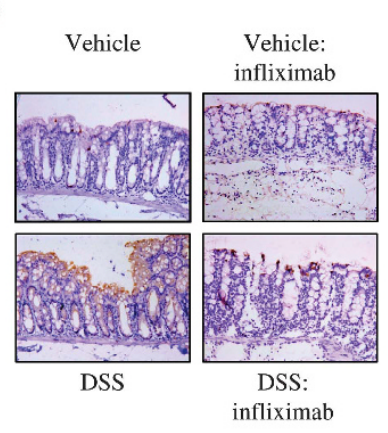

TUNEL f

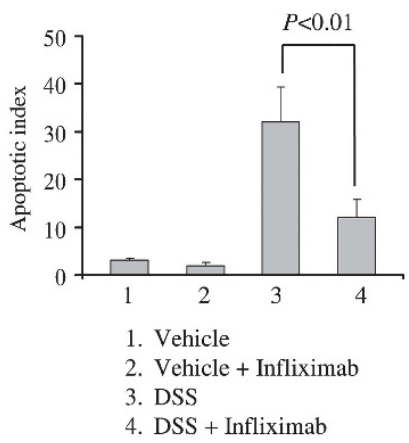

g

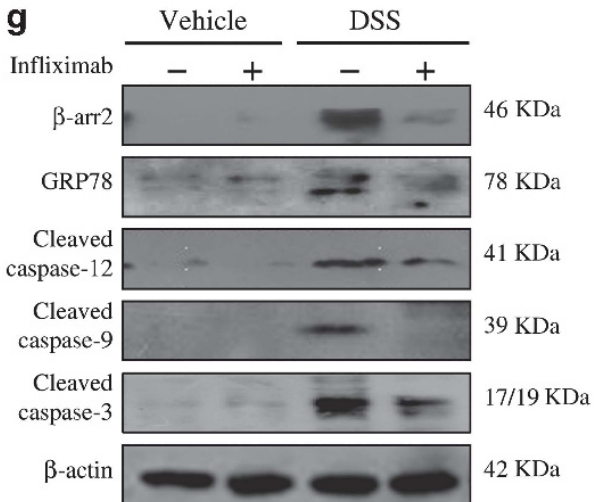

Figure 5 Inhibition of TNF- $\alpha$-alleviated mucosal apoptosis by downregulating $\beta$-arr2 in colitis. WT mice were treated with $5 \%$ DSS alone or in combination with infliximab. (a) The disease activity index was determined at the indicated time points, as described in the Methods section. ${ }^{*} P<0.01$ compared with DSS + Infliximab mice. (b) Colonoscopic imaging was obtained alone or in combination with infliximab on day 5 and showed that the colitis was obviously alleviated after infliximab treatment. (c, d) The colonic sections were stained with hematoxylin and eosin (H\&E; original magnification, $\times 200$ ), and the histological damage was scored after H\&E staining. The results demonstrated that the mucosal injury was distinctly relieved following infliximab treatment. (e, f) TUNEL staining indicated that apoptosis was attenuated after infliximab treatment (original magnification, $\times 200$ ), and the apoptotic index was depressed. (g) $\beta$-arr2, GRP78, cleaved caspase-12, cleaved caspase-9, and cleaved caspase-3 protein expression were downregulated after infliximab administration. The values in c and e are the mean \pm s.d. ( $n=6$ in each group). DSS, dextran sulfate sodium salt; GRP78, glucose-regulated protein 78; TNF- $\alpha$, tumor necrosis factor- $\alpha$; TUNEL, terminal deoxynucleotidyl transferase dUTP nick end labeling; WT, wild type; $\beta$-arr2, $\beta$-arrestin 2.

\section{$\beta$-Arr2 depended on ER stress/PUMA apoptotic signaling in colitis}

Our previous study demonstrated that PUMA mediates intestinal epithelial apoptosis in colitis. ${ }^{10}$ Other investigations have shown that PUMA appears to be critical for ER stressinduced apoptosis. ${ }^{25}$ To investigate the role of PUMA in ER stress-induced intestinal epithelial apoptosis in colitis, PUMA KO mice were used in this study. Although PUMA deficiency significantly attenuated intestinal mucosal damage and caspase- 3 activation in colitis, it did not affect GRP78 expression or caspase-12 activation (Figure $7 \mathbf{a}-\mathbf{c}$ ). In addition, the targeted deletion of PUMA did not affect tunicamycin-induced ER stress signaling in mice (Figure 7d). A TUNEL assay showed that intestinal mucosal apoptosis was remarkably inhibited in the PUMA KO mice compared with the WT mice (Figure 7e). Furthermore, double immunofluorescence staining of PUMA and GRP78 indicated that the proteins partly localized in the same cells in mice with colitis (Figure 7f). Therefore, PUMA is required for ER stress-induced epithelial apoptosis in colitis.

A luciferase assay was used to confirm whether $\beta$-arr2 targeted ER stress/PUMA. PUMA luciferase reporters were transfected with the $\beta$-arr 2 plasmid along with the control pcDNA3.0 vector into HCT116 cells. The results showed that the PUMA reporter was activated by $\beta$-arr 2 , and the treatment with the ER stress inhibitor salubrinal repressed PUMA reporter activation (Figure 8a). Furthermore, treating HCT116 cells with TNF- $\alpha$ showed that GRP78, cleaved caspase-4 (also known as caspase-12 in mice) and PUMA were gradually upregulated after $\beta$-arr2 induction, following an increase in the TNF- $\alpha$ dose (Figure $\mathbf{8 b}$ ). ER stress is activated by p-eIF $2 \alpha$ that reflects the activation of the PERK signaling branch. ${ }^{26}$ Furthermore, HCT116 cells were transfected with a GFP- $\beta$ arr 2 plasmid, and $\beta$-arr 2 overexpression significantly enhanced GRP78 upregulation, eIF2 $\alpha$ phosphorylation, and caspase- 4 activation, thus activating ER stress signaling (Figure $8 \mathrm{c}$ and $\mathrm{d}$ ). After tunicamycin treatment, double immunofluorescence staining showed that PUMA was associated with GRP78 in these cells and that PUMA mediated tunicamycin-induced cell apoptosis (Figure 8e and $\mathbf{f}$ ). The data suggest that the effect of $\beta$-arr2 depends on ER stress/PUMA apoptotic signaling.

\section{Inflammation enhanced ER stress/PUMA signaling via ק-arr2}

Our above data showed that $\beta$-arr2 enhanced ER stress signaling. However, whether the effect of $\beta$-arr 2 is triggered by interacting with eIF2- $\alpha$ is unclear. To confirm the mechanism, 
a

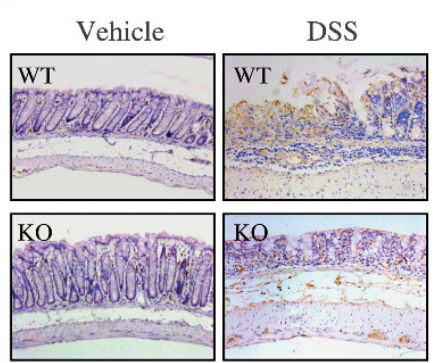

GRP 78 b
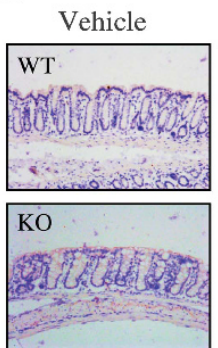

Cleaved caspase 12

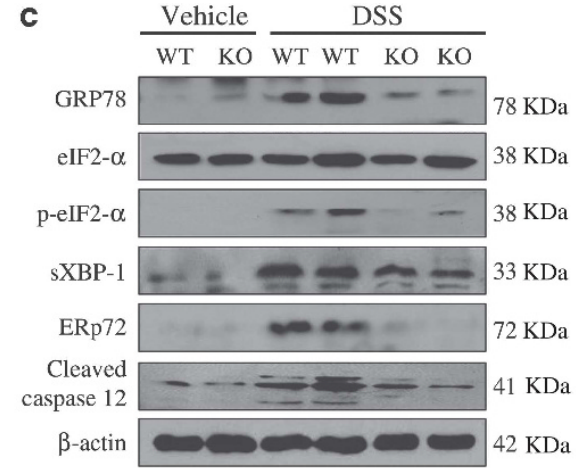

e

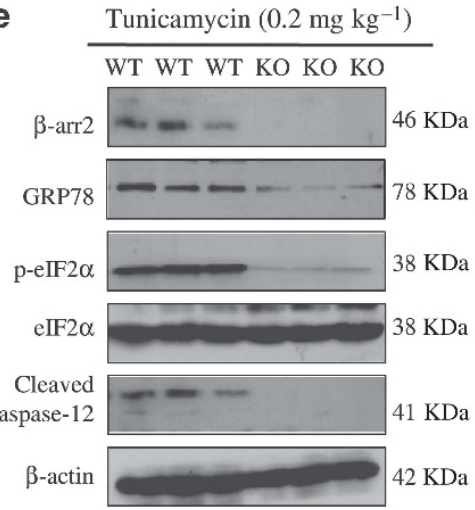

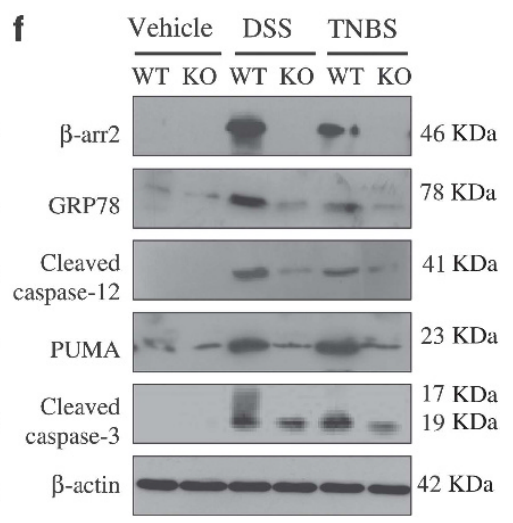

Figure $6 \beta$-Arr2 mediated mucosal apoptosis by ER stress signaling in colitis. $\beta$-Arr2 KO and WT mice were treated with $5 \%$ DSS. (a, b) GRP78 and cleaved caspase-12 were increased as detected by immunohistochemical staining. The increasing trend in $\beta$-arr2 KO mice was less dramatic (original magnification, $\times 200$ ). (c) ER stress was analyzed by western blotting in colonic mucosal tissue ( $n=6$ in each group). In conditions of $\beta$-arr2 deficiency, the ER stress was downregulated. (d) $\beta$-arr2 KO and WT mice were subjected to TNF- $\alpha\left(40 \mu \mathrm{g} \mathrm{kg}^{-1}\right)$ intraperitoneal injection. Related molecular of ER stress was attenuated in $\beta$-arr2 KO mice compared with WT mice ( $n=6$ in each group). (e) For ER stress induction, the mice were subjected to $0.2 \mathrm{mg} \mathrm{kg}^{-1}$ tunicamycin intraperitoneal injection, and the ER stress was alleviated in $\beta$-arr2 KO mice ( $n=6$ in each group). (f) Colonic epithelial cells were isolated from colonic mucosa of the treated mice as described in the Methods. Western blot analysis of the indicated proteins in colonic epithelial cells of DSS- or TNBS-treated mice ( $n=6$ in each group). ER, endoplasmic reticulum; DSS, dextran sulfate sodium salt; GRP78, glucose-regulated protein 78; KO, knockout; PUMA, p53-upregulated modulator of apoptosis; TNF- $\alpha$, tumor necrosis factor- $\alpha$; TNBS, 2,4,6-trinitrobenzenesulfonic acid; WT, wild type; $\beta$-arr2, $\beta$-arrestin 2.

the interaction between $\beta$-arr2 and eIF2- $\alpha$ in mammalian cells was analyzed by co-immunoprecipitation. The full-length human $\beta$-arr2 was fused to the GAL4 DNA-binding domain as a bait in the yeast two-hybrid system to screen a mouse fetal brain complementary DNA library, and eIF2- $\alpha$, one of the critical transcription factors in the PERK branch of the UPR, was identified as a binding partner of $\beta$-arr2. The interaction between $\beta$-arr2 and eIF2- $\alpha$ was examined in expressed HCT116 cells by co-immunoprecipitation after TNF- $\alpha$ stimulation. The results showed that $\beta$-arr2 directly interacted with eIF2- $\alpha$ in the inflammatory response (Figure 9a).

$\beta 2$-Adrenergic receptor ( $\beta 2 \mathrm{AR}$ ) agonist is able to increase the association of $\beta$-arrs with its partner Src. ${ }^{27}$ Therefore, the interactive effect of $\beta$-arr2 and eIF2- $\alpha$ was examined after $\beta 2 A R$ agonist treatment. After the HCT116 cells co-expressed $\beta$-arr2, eIF2- $\alpha$, and $\beta 2 A R$, the cells were stimulated by the $\beta 2 A R-$ specific agonist isoproterenol. A co-immunoprecipitation showed that an increase in $\beta$-arr2-bound eIF2- $\alpha$ was clearly detected after $2 \mathrm{~min}$ of agonist exposure and peaked at $5 \mathrm{~min}$ (Figure 9b). To further detect the mitochondrial-related mechanisms, the interaction between PUMA and eIF2- $\alpha$ was also examined in expressed HCT116 cells after TNF- $\alpha$ stimulation, and the result showed that PUMA interacted well with eIF2- $\alpha$ in inflammatory stimulation (Figure 9c). The data indicated that inflammation enhances ER stress/PUMA signaling via $\beta$-arr2 interacting with eIF2- $\alpha$.

\section{ER stress/PUMA-induced mitochondrial apoptotic signaling}

PUMA can mediate mitochondria-dependent and mitochondria-independent apoptosis in several tissues and cells. ${ }^{28}$ After tunicamycin treatment, $\beta$-arr2 expression was unaffected; however, GRP78, PUMA, cleaved caspase-9, and cleaved caspase-3 were significantly increased (Figure 10a). We knocked down PUMA expression using small interfering RNA (siRNA) and then induced ER stress signaling via tunicamycin treatment. The results showed that apoptosis was markedly inhibited and that the caspase- 9 and caspase- 3 activation were significantly suppressed by PUMA siRNA after tunicamycin treatment (Supplementary Figure S5 and 


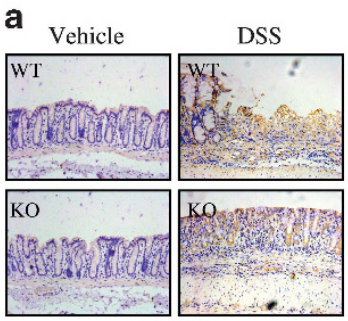

GRP 78

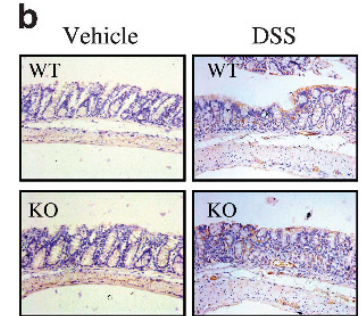

Cleaved caspase 12
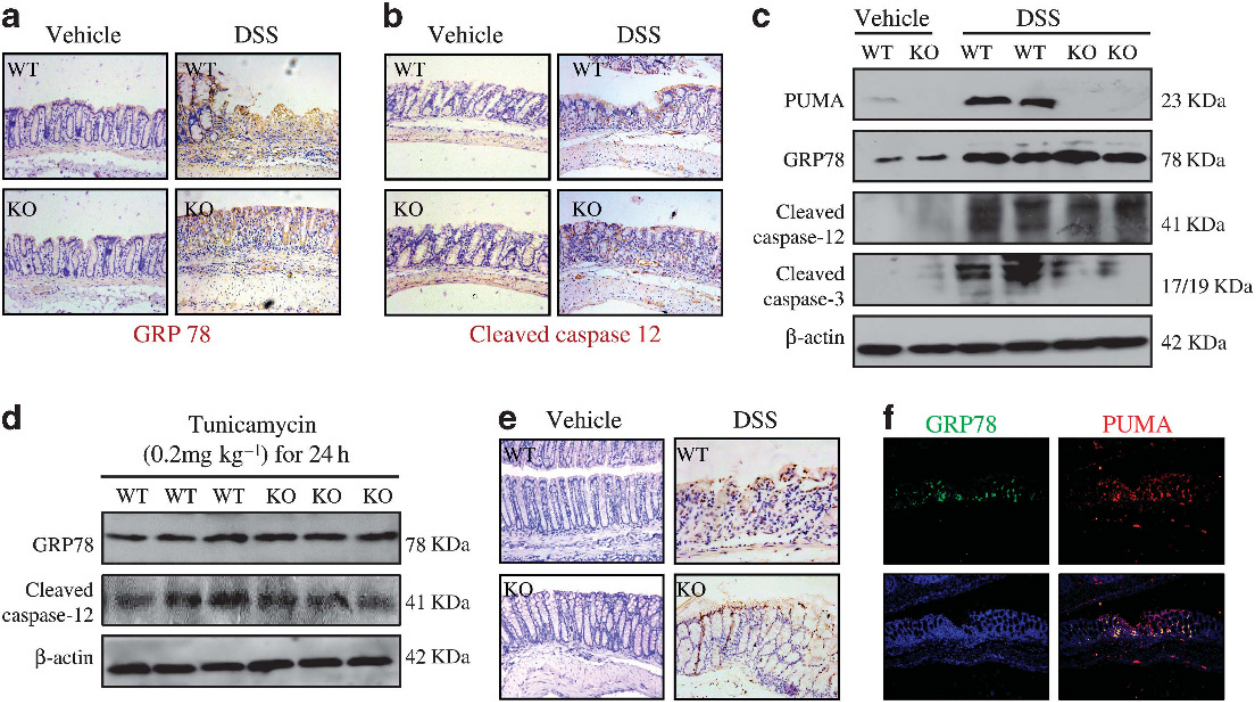

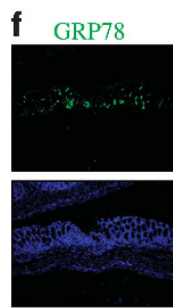

DAPI

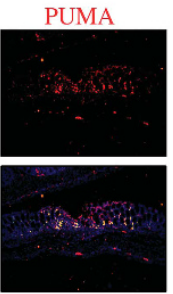

Merge

Figure 7 PUMA was required for ER stress-induced epithelial apoptosis in colitis. PUMA KO and WT mice were treated with $5 \%$ DSS. (a, b) The expression of GRP78 and cleaved caspase-12 were increased compared with vehicle; however, the PUMA KO did not affect the expression (original magnification, $\times 200$ ). (c) The PUMA deficiency suppressed caspase-3 activation but not GRP78 expression and caspase-12 activation ( $n=6$ in each group). (d) The PUMA deficiency did not affect tunicamycin-induced ER stress. (e) Apoptosis was attenuated in PUMA KO mice compared with WT mice after DSS treatment (original magnification, $\times 200$ ). (f) Double staining of PUMA and GRP78 was shown in WT mice after DSS treatment, and the result indicated that PUMA responds to ER stress (original magnification, $\times 200$ ). ER, endoplasmic reticulum; DSS, dextran sulfate sodium salt; GRP78, glucose-regulated protein 78; KO, knockout; PUMA, p53-upregulated modulator of apoptosis; WT, wild type.
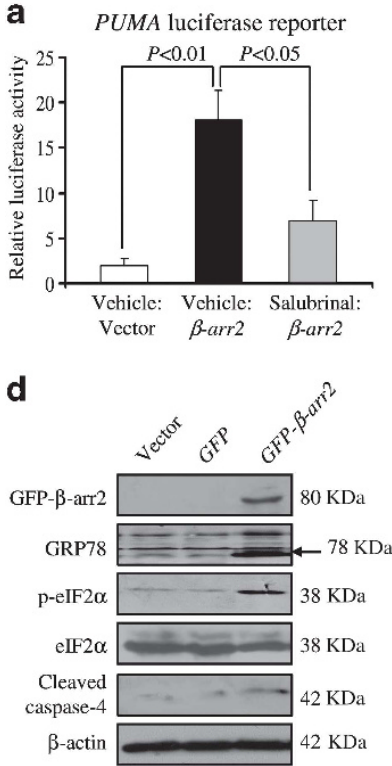

b

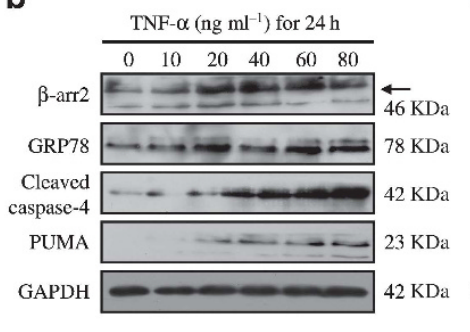

e

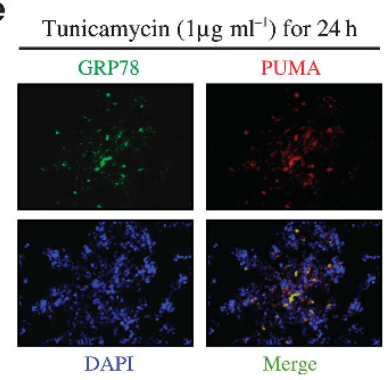

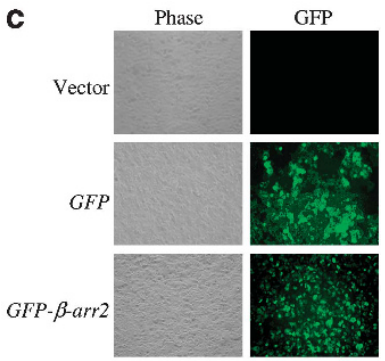

f

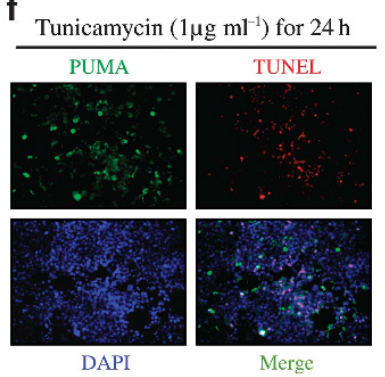

Figure $8 \beta$-Arr2-mediated apoptosis by ER stress was dependent on PUMA signaling in vitro. (a) $\beta$-Arr2 activated a PUMA luciferase reporter; however, the ER stress inhibitor salubrinal suppressed this activation. (b) The protein levels of $\beta$-arr2, GRP78, and PUMA increased in a dose-dependent manner after TNF- $\alpha$ treatment in HCT116 cells. (c, d) The overexpression of $\beta$-arr2 promoted GRP78 upregulation, elF2 $\alpha$ phosphorylation, and caspase-4 activation. (e) Double staining of PUMA and GRP78 in HCT116 cells after treatment with the ER stress inducer tunicamycin. (f) Double staining of PUMA and TUNEL in HCT116 cells after tunicamycin treatment. ER, endoplasmic reticulum; GRP78, glucose-regulated protein 78; PUMA, p53-upregulated modulator of apoptosis; TNF- $\alpha$, tumor necrosis factor- $\alpha$; TUNEL, terminal deoxynucleotidyl transferase dUTP nick end labeling; $\beta$-arr2, $\beta$-arrestin 2 .

Figure $10 \mathbf{b}$ and $\mathbf{c})$. However, PUMA siRNA did not affect $\beta$-arr2 or GRP78 expression (Figure 10c). Furthermore, tunicamycin-treated HCT116 cells exhibited Bax cytosolic accumulation and mitochondrial cytochrome $c$ release, which triggered mitochondrial apoptotic signaling, and PUMA siRNA inhibited tunicamycin-induced mitochondrial apoptotic 
a

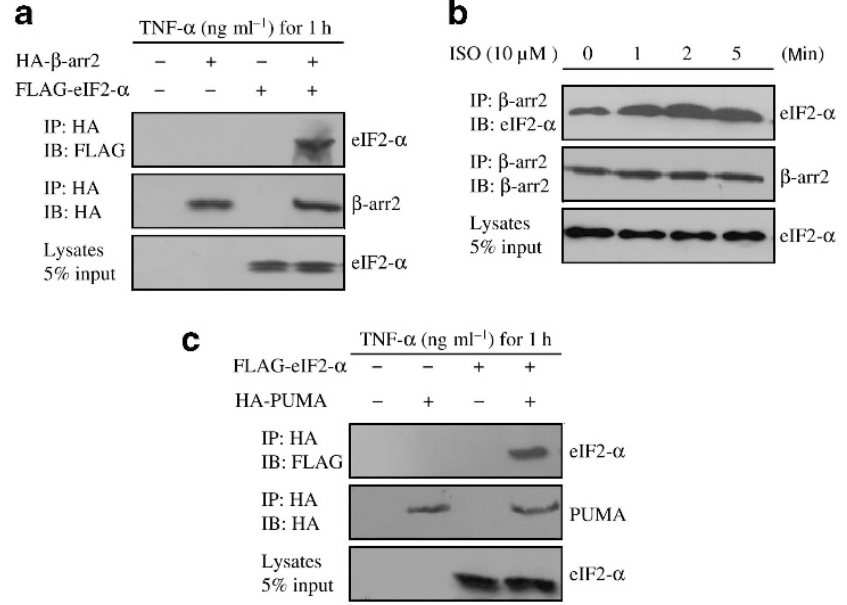

Figure $9 \quad \beta$-Arr2 enhanced ER stress via interacting with elF2- $\alpha$. (a) $\beta$-arr2 interacted with elF2 $\alpha$. HCT116 cells were cotransfected with FLAG-elF2 $\alpha$ and HA- $\beta$-arr2 as indicated. After TNF- $\alpha$ treatment for $1 \mathrm{~h}$, the cells were collected, and then the cellular lysates were subjected to immunoprecipitation with an anti-HA antibody. Coimmunoprecipitated elF2 $\alpha$ was detected with an anti-FLAG antibody. (b) After co-transfection of GFP- $\beta_{2}$ AR, HA- $\beta$-arr2, and FLAG-elF2 $\alpha$, the HCT116 cells were challenged with $10 \mu \mathrm{m}$ isoproterenol (ISO) for the indicated time, and then the cells were subjected to immunoprecipitation with an anti- $\beta$-arr2 antibody. Coimmunoprecipitated elF2 $\alpha$ was detected with an anti-elF2 $\alpha$ antibody. (c) PUMA interacted with elF2 $\alpha$. HCT116 cells were cotransfected with FLAG-eIF2 $\alpha$ or HA-PUMA as indicated, and then the cells were subjected to immunoprecipitation with anti-HA antibody. Coimmunoprecipitated elF2 $\alpha$ was detected with anti-FLAG antibody. elF2- $\alpha$, eukaryotic initiation factor 2; ER, endoplasmic reticulum; GRP78, glucose-regulated protein 78; IB, immunoblot; IP, immunoprecipitate; PUMA, p53-upregulated modulator of apoptosis; siRNA, small interfering RNA; TNF- $\alpha$, tumor necrosis factor- $\alpha ; \beta$-arr2, $\beta$-arrestin 2. signaling (Figure 10d). These data demonstrate that $\beta$-arr2 induces apoptosis via ER stress and the PUMA-mediated mitochondrial apoptotic pathway.

\section{DISCUSSION}

Our previous study demonstrated that PUMA-induced epithelial cell apoptosis contributes to colitis ${ }^{10}$ however, the signaling that is involved in PUMA-induced apoptosis in colitis is unclear. In this study, we demonstrated that $\beta$-arr2 mediated the PUMA-induced epithelial and goblet cell apoptosis via ER stress in colitis and in a cultured human cell model. The $\beta$-arrs were originally discovered due to their role in GPCR desensitization and are now thought to have a much broader role in cell signaling. ${ }^{6-8} \mathrm{~A}$ recent study demonstrated that $\beta$-arr1 deficiency protected mice from experimental colitis. ${ }^{4}$ In this study, we found that increased $\beta$-arr2 expression correlates with colitis and PUMA induction in human UC and CD and that a complete $\beta$-arr2 KO ameliorated DSS- and TNBSinduced colitis and intestinal mucosal apoptosis in mice. The data demonstrated that $\beta$-arr2 is a critical mediator of mucosal apoptosis and a significant modulator of UC and indicated that $\beta$-arr2 has a pivotal role in PUMA-induced IEC and goblet cell apoptosis in colitis. In this study, the induction of $\beta$-arr 2 could be detected throughout the DSS or TNBS treatment; this induction was a response to inflammatory mediators, including TNF- $\alpha$. PUMA induction by DSS or TNBS is driven partly by TNF- $\alpha$. Furthermore, the inhibition of TNF- $\alpha$ alleviated mucosal apoptosis by downregulating $\beta$-arr2, and $\beta$-arr2 function depended on ER stress-mediated apoptotic signaling a

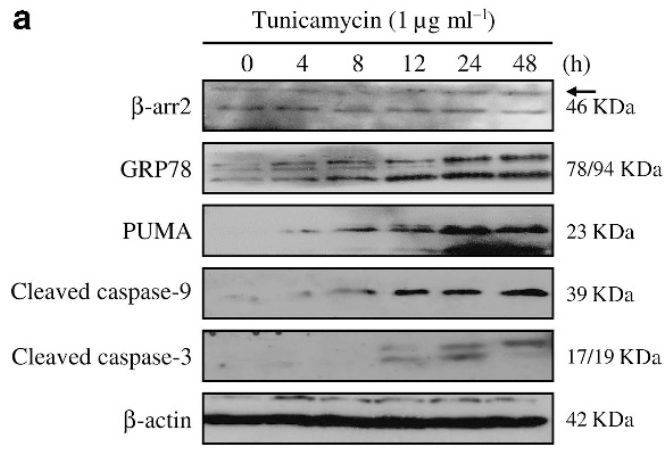

b

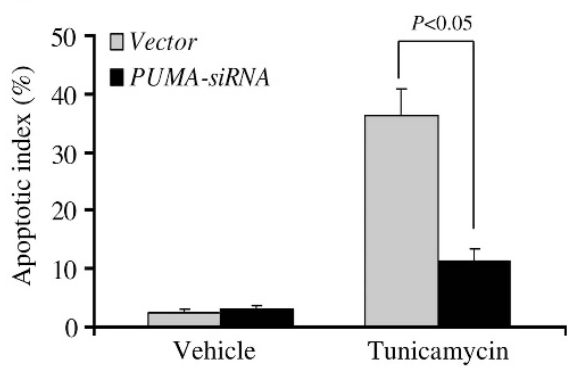

C

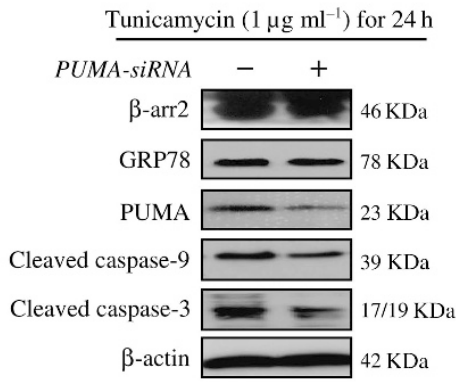

d

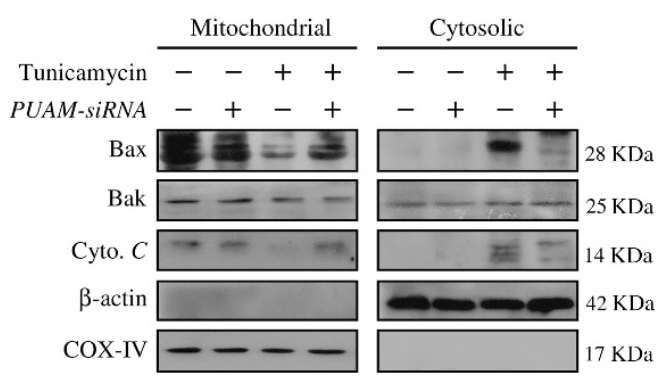

Figure 10 ER stress-induced mitochondrial apoptotic signaling through PUMA. (a) PUMA, active caspase-9, and active caspase-3 were increased following the increase in GRP78 in a time-dependent manner after tunicamycin treatment. (b) PUMA siRNA downregulated tunicamycin-induced apoptosis. (c) The knockdown of PUMA repressed the activation of caspase-9 and caspase-3, but not $\beta$-arr2 and GRP78, after tunicamycin treatment. (d) The knockdown of PUMA restrained tunicamycin-induced mitochondrial apoptotic signaling. ER, endoplasmic reticulum; GRP78, glucose-regulated protein 78; PUMA, p53-upregulated modulator of apoptosis; siRNA, small interfering RNA; $\beta$-arr2, $\beta$-arrestin 2. 
in colitis. Using $\beta$-arr $2 \mathrm{KO}$ mice, we demonstrated that a $\beta$-arr2 deficiency improved colitis, mucosal damage, and epithelial and goblet cell apoptosis and markedly repressed ER stress. Furthermore, our data showed that PUMA is essential for ER stress-mediated apoptosis.

Although the $\beta$-arrs were originally discovered due to their role in GPCR desensitization, recent studies have demonstrated that they have a much broader role in cell signaling. ${ }^{6-8} \beta$-arr1 deficiency decreased IL- 6 production and enhanced IL-10 and IL-22 in the colon, protecting mice from experimental colitis. ${ }^{4}$ Our data showed that the induction of $\beta$-arr2 occurred within $24 \mathrm{~h}$ after DSS or TNBS treatment and could be detected throughout the treatment. This rapid and sustained $\beta$-arr2 induction was a downstream inflammatory response, as cytokine induction and lymphocyte infiltration could still be detected in $\beta$-arr $2 \mathrm{KO}$ mice. The induction of $\beta$-arr2 by DSS is driven partly by TNF- $\alpha$, which is the major cytokine that initiates and perpetuates intestinal inflammation. ${ }^{29}$ Blocking TNF- $\alpha$ activity could effectively ameliorate the inflammation in IBD. ${ }^{26}$ Interestingly, ER stress activation, a key mediator of $\mathrm{IBD}$, was downregulated in $\beta$-arr $2 \mathrm{KO}$ mice compared with WT mice.

$\beta$-Arr2 has been established as an important modulator of GPCR signaling, and eIF $2 \alpha$ is the master regulator of ER stress function. Under normal circumstances, the cellular concentration of eIF $2 \alpha$ is maintained at low levels. In this study, we demonstrated that under inflammatory stimulation via TNF- $\alpha$, $\beta$-arr2 directly interacted with eIF $2 \alpha$, thus providing a solid basis for the functional consequence of the $\beta$-arr2 and eIF $2 \alpha$ interaction. Our study further revealed that the association of $\beta$-arr2 and eIF $2 \alpha$ was significantly promoted by the activation of GPCRs. The activation of GPCRs by various extracellular signals significantly increases the binding of $\beta$-arr2 and eIF $2 \alpha$ and thus effectively activated UPR signaling. The functional consequences of the enhanced $\beta$-arr2 and eIF2 $\alpha$ interaction are on one hand to promote $\beta$-arr2 ubiquitination and assist GPCR internalization and on the other hand, to modulate the eIF2/ER stress feedback loop and reduce the misfolded proteins. In summary, the current study strongly suggests a potential role for GPCR signaling in the modulation of ER stress-mediated apoptosis and clearly indicates that $\beta$-arr2 may serve as a signaling linker between the GPCR and ER stress pathways. Furthermore, the link between $\beta$-arr2-mediated ER stress and mitochondrial-related mechanisms was demonstrated by the interaction of PUMA and $\operatorname{eIF} 2 \alpha$.

ER stress triggers a series of signaling and transcriptional events known as the UPR. The UPR attempts to restore homeostasis in the ER, but if it is prolonged, it can trigger apoptosis in the stressed cells. ${ }^{30} \mathrm{ER}$ stress is a common feature in intestinal secretory cells such as Paneth cells, enteroendocrine cells, and goblet cells. ${ }^{31}$ Recently, multiple singlenucleotide polymorphisms in XBP1 were found to be associated with both UC and CD. ${ }^{12}$ Various studies report increased GRP78 levels, indicating the activation of ER stress, in colonic and ileal samples from IBD patients. ${ }^{32-34}$ Consistent with these data, our results demonstrated that the colonic GRP78 transcript and/or protein levels were significantly increased in patients with UC and colitis mice, and sXBP1, p-eIF $2 \alpha$, and ERp72 were increased in these colitis samples. However, these increases, especially the increase in p-eIF $2 \alpha$, a critical transcription factor in the PERK branch of the UPR, were clearly downregulated in $\beta$-arr2-deficient mice following DSS and tunicamycin treatment.

Recent studies have demonstrated that PUMA-mediated ER stress induces apoptosis in various cell types and in different diseases. ${ }^{35-37}$ PUMA induces apoptosis by activating the caspases through mitochondrial dysfunction. ${ }^{38,39}$ Our data showed that ER stress was involved in epithelial and goblet cell apoptosis via PUMA using PUMA KO mice with colitis, and we demonstrated that apoptosis induced by the ER stress initiator tunicamycin was significantly inhibited by interference with the PUMA gene in vitro. Tunicamycin administration led to the cytosolic accumulation of cytochrome $c$, and the release of cytochrome $c$ from mitochondria was decreased using PUMA siRNA. These results indicated that ER stress/PUMA-mediated apoptosis depends on the mitochondrial apoptotic pathway in colitis.

In summary, our data showed that intestinal inflammation significantly induced $\beta$-arr2 expression, that $\beta$-arr2 activated mucosal ER stress, that ER stress upregulated PUMA, and that PUMA induced mucosal apoptosis in colitis through the mitochondrial apoptotic pathway. These results suggest that $\beta$-arr2 promotes inflammation-induced epithelial and goblet cell apoptosis through ER stress/PUMA in colitis and that $\beta$-arr2 is a potential therapeutic target for UC.

\section{METHODS}

Tissue samples. Frozen specimens from patients with UC were obtained from the Gastroenterology Department of the Third Affiliated Hospital of the Sun Yat-Sen University. The acquisition of the tissue samples was approved by the Institutional Review Board at Sun Yat-Sen University. Written informed consent was obtained from each patient before inclusion in the study.

Mice and treatment. All animal experiments were approved by the Institutional Animal Care and Use Committee at Sun Yat-Sen University. WT mice in the C57BL/6J background and the PUMA ${ }^{-/-}$ mice (Jackson Laboratory, ME) were identified by genotyping using PCR as previously described. ${ }^{28}$ The original $\beta$-arr 2 heterozygous mice in the C57BL/6J background were obtained from Dr Robert J Lefkowitz (Duke University Medical Center, Durham, NC). Mice were generated by breeding and were identified by PCR genotyping with genomic DNA from the tails of 4-week-old mice (Supplementary Table S1 and Supplementary Figure S6). ${ }^{40}$ The animals were housed at four to five mice per cage at $22-24^{\circ} \mathrm{C}$ in rooms with $50 \%$ humidity and a $12-\mathrm{h}$ light-dark cycle. All animals were given mouse chow and water ad libitum. Eight- to 10-week-old mice were used for all experiments. For colitis induction, mice were fed 5\% DSS (MP Biomedicals, Solon, OH) in the drinking water. For the TNBS treatment, mice were presensitized on the skin for 1 week with TNBS (Sigma-Aldrich, St Louis, MO) at $40 \mathrm{mg} \mathrm{kg}^{-1}$ body weight in $50 \%$ ethanol. After fasting overnight, the presensitized mice received $100 \mathrm{mg} \mathrm{kg}^{-1} \mathrm{TNBS}$ by rectal injection with a $1-\mathrm{ml}$ syringe fitted with a catheter, as previously described. ${ }^{10}$ For the ER stress inhibition or induction, mice were injected with $1 \mathrm{mg} \mathrm{kg}^{-1}$ salubrinal (Santa Cruz, Santa Cruz, CA) or $0.2 \mathrm{mg} \mathrm{kg}^{-1}$ tunicamycin (Sigma-Aldrich) $1 \mathrm{~h}$ before the DSS 
treatment once daily. To induce inflammation, mice were injected with $40 \mu \mathrm{g} \mathrm{kg}^{-1}$ TNF- $\alpha$ (PeproTech, Hamburg, Germany) $2 \mathrm{~h}$ before killing. At the end of the experiment, mice were killed after anesthesia with $350 \mathrm{mg} \mathrm{kg}^{-1}$ of $10 \%$ chloral hydrate intraperitoneal injection.

MPO assay. MPO activity was assessed essentially as previously described. ${ }^{41}$ Colon specimens were homogenized in $0.5 \%$ hexadecyltrimethylammonium bromide in $50 \mathrm{~mm}$ phosphate buffer $(\mathrm{pH}$ 6.0) and sonicated for $10 \mathrm{~s}$. Suspensions were freeze-thawed three times and then centrifuged at 15,000 r.p.m. for $15 \mathrm{~min}$. One hundred microliters of supernatant was mixed with a solution of $0.167 \mathrm{mg} \mathrm{ml}^{-1}$ O-dianisidine hydrochloride and $0.0005 \%$ hydrogen peroxide. MPO activity was measured spectrophotometrically as the change in absorbance at $460 \mathrm{~nm}$.

Colonoscopic assessment. On experimental days 3,5 , and 7 , animals were anesthetized and examined with a flexible fiberscope with a diameter of $2.8 \mathrm{~mm}$ (Olympus, Tokyo, Japan) assembled to a video camera for recording images and counting ulceration. Colon injury was scored by two independent observers using an adapted endoscopic index of colitis. ${ }^{42}$ The following parameters were analyzed and graded as 0 (absent) or 1 (present) each: changes in the vascular pattern, mucosal granularity, strictures, bleeding, and ulcers (total score ranging from 0 to 5 ).

Immunofluorescent staining of colon sections. Paraffinized embedded tissues from three randomly selected animals from each group were used to prepare sections. For immunohistochemical staining, $5-\mu \mathrm{m}$ paraffinized sections were fixed with $4 \%$ paraformaldehyde in phosphate-buffered saline for $15 \mathrm{~min}$ and then permeabilized with $1 \%$ Triton-X-100 for $30 \mathrm{~min}$, followed by three phosphate-buffered saline washes. Then, the targeted protein was detected using a secondary antibody followed by detection using the $\mathrm{ABC}$ staining system, and sections were counterstained with hematoxylin. For immunofluorescence staining, the targeted protein was detected by a related secondary antibody. Antibody-antigen complexes were visualized by incubating with a biotin-conjugated secondary antibody and streptavidin Alexa 488 or 594 (Molecular Probes, Carlsbad, CA), and the nuclei were counterstained with $2 \mathrm{mg} \mathrm{ml}^{-1} 4^{\prime}$,6-diamidino-2-phenylindole dihydrochloride (Molecular Probes). For double staining, after finishing the first protein detection, the slides were stained again to detect the second protein. Immunohistochemical, immunofluorescence, and double staining were performed using antibodies for $\beta$-arr2 (obtained from Dr Robert J. Lefkowitz), PUMA (Abcam, Cambridge, MA), GRP78 (Enzo Life Sciences, Switzerland) and cleaved caspase-3 (Cell Signaling Technology, Danvers, MA).

Determination of the disease activity index score. The murine colitis phenotypes were measured by disease activity index score, which is the sum of body weight, diarrhea, and bleeding scores determined daily during the treatment as previously described. ${ }^{20}$ All scores were relative to the scores on day 1 , which were set as 0 . For body weight, no loss was scored as 0 , a loss of $1-5 \%$ weight was scored as $1,6-10 \%$ as $2,11-20 \%$ as 3 , and higher than $20 \%$ as 4 . For stool consistency, 0 was scored for well-formed stool pellets, 2 for pasty and semiformed stools that did not adhere to the anus, and 4 for liquid stools that adhered to the anus. For bleeding, which was analyzed by the Hemoccult fecal occult blood test (Beckman Coulter, Fullerton, CA), 0 was assigned for no blood, 2 for positive Hemoccult, and 4 for gross bleeding. All scores were blindly confirmed by trained independent individuals.

Analysis of tissue damage and histology. Entire colons were collected from the treated mice and were fixed flat between wet filter papers in $10 \%$ neutral buffered formalin for $48 \mathrm{~h}$. Paraffin-embedded sections $(5 \mu \mathrm{m})$ were subjected to hematoxylin and eosin staining for histological analysis. Histological scores were determined blindly based on the previously described criteria: 0 , normal; 1 , moderate mucosal inflammation without erosion and ulcer; 2 , severe mucosal inflammation with erosion; 3 , severe mucosal inflammation with ulcer $(<1 \mathrm{~mm})$; 4 , severe mucosal inflammation with ulcer $(1-3 \mathrm{~mm})$; and 5 , severe mucosal inflammation with ulcer $(>3 \mathrm{~mm}){ }^{21}$

Cell culture. The human colorectal cancer cell line HCT116 was routinely cultured in McCoy's 5a medium supplemented with $10 \%$ fetal bovine serum, $30 \mathrm{U} \mathrm{ml}^{-1}$ penicillin, and $30 \mathrm{mg} \mathrm{ml}^{-1}$ streptomycin at $37^{\circ} \mathrm{C}$ under $5 \% \mathrm{CO}_{2}$.

siRNA. HCT116 cells were cultured in six-well plates. For PUMA siRNA treatment, cells were transfected with $20 \mu \mathrm{m}$ PUMA RNA oligo kit (GenePharma, Suzhou, China). The PUMA siRNA sequence targeted the coding region of the PUMA mRNA, and three sequences were purchased: siRNA-1 (5'-GACUUUCUCUGCACCAUGUTT$\left.3^{\prime}\right)$; siRNA-2 (5'-GGGUCCUGUACAAUCUCAUTT- $\left.3^{\prime}\right)$; and siRNA3 (5'-CUGUACAUGUUUGGUUAAUTT- $\left.3^{\prime}\right)$. The most effective sequence was selected. After incubating for $24 \mathrm{~h}$, the transfection medium was replaced by regular culture medium before tunicamycin administration. A siRNA directed against glyceraldehyde-3-phosphate dehydrogenase provided in the kit was used as a control. After these cells had grown to $90 \%$ confluency, $1 \mu \mathrm{g} \mathrm{ml}^{-1}$ tunicamycin was added for $24 \mathrm{~h}$.

PUMA reporter assay. HCT116 cells were plated in 96-well plates and transfected with the expression plasmid $p c D N A 3.0-\beta$-arr2-GFP or the vector $p c D N A 3.0-G F P$ (400 ng each) (kindly provided by Dr Pei G, Chinese Academy of Sciences, Shanghai) using Lipofectamine 2000 (Invitrogen, Carlsbad, CA). For each transfection, $100 \mathrm{ng}$ of the pGL4-PUMA luciferase reporter plasmid (Addgene, Cambridge, MA) and $5 \mathrm{ng}$ of the renilla control plasmid were used. Next, the cells were serum starved overnight and then treated with $10 \mu \mathrm{M}$ salubrinal (Santa Cruz). After treatment, the cells were collected, washed once with phosphate-buffered saline, and analyzed with a Dual-Luciferase reporter assay system (Promega, WI) according to the manufacturer's instructions with a Lumat LB 9507 luminometer (Berthold, Nashua, NH).

Analysis of apoptosis. TUNEL staining was performed using the ApopTag kit (Roche, Basel, Switzerland) according to the manufacturer's instructions. TUNEL-positive crypts were counted in 100 randomly selected crypts. Six mice from each group were studied. Bax/ Bak and cytochrome $c$ release was analyzed by western blot probing of mitochondrial and cytosolic fractions isolated from intestinal mucosal scraping by differential centrifugation. ${ }^{28}$ Caspase- 3 activity was measured by western blotting for active caspase-3 (Cell Signaling Technology).

Real-time PCR. Total RNA was extracted using ISOGEN (Nippon Gene, Toyama, Japan). Reverse-transcription of RNA to cDNA was performed using a RNA LA PCR Kit (Takara Bio, Shiga, Japan). Realtime PCR was performed using a SYBR Green master mixture (Invitrogen) on a HT7900 system (Applied Biosystems, Grand Island, $\mathrm{NY}$ ). The expression levels of $\beta$-arr $2, I L-1 \alpha, I L-1 \beta, I L-6, T N F-\alpha, I C A M-$ 1 , VCAM-1, and $\beta$-actin in DSS-treated mice were determined by realtime PCR using specific primers shown in Supplementary Table S2.

IECs isolation. Dissected mouse colons were cut open longitudinally and incubated in 50-ml tubes with $20 \mathrm{ml} \mathrm{Ca}^{2+}$ - and $\mathrm{Mg}^{+}$-free Hank's Buffered Salt Solution (CMF-HBSS; Invitrogen) containing $10 \mathrm{~mm}$ dithiothreitol and $1.5 \mathrm{~mm}$ EDTA at $4{ }^{\circ} \mathrm{C}$ for $1 \mathrm{~h}$. After incubation, the tube was vigorously shaken for $2 \mathrm{~min}$ to dislodge IECs. The cell suspensions were passed through a $100-\mu \mathrm{m}$ cell strainer (BD Biosciences, Franklin Lakes, NJ) and were centrifuged at room temperature at $400 \mathrm{~g}$ for $5 \mathrm{~min}$. The cell pellet was resuspended in $2 \mathrm{ml} \mathrm{CMF-}$ HNBSS and incubated at $4{ }^{\circ} \mathrm{C}$ for $1 \mathrm{~h}$ with agitation with a premade mixture of $100 \mu \mathrm{l} \mathrm{TBS}, 5 \mu \mathrm{l}$ rat anti-mouse epithelial cell adhesion molecule, and $50 \mu \mathrm{l}$ anti-rat IgG Danabeads (Invitrogen). The beads were isolated by a Magnetic Particle Concentrator (Invitrogen) and washed three times with CMF-HBSS. The isolated IECs were stained for epithelial cell adhesion molecule and also lysed for western blotting. 
Immunoprecipitation and western blotting. The cells were lysed in lysis buffer (50 mm Tris-HCl, pH 7.5, 1 mm EDTA, $150 \mathrm{~mm} \mathrm{NaCl,} 20 \mathrm{~mm}$ $\mathrm{NaF}, 0.5 \%$ Nonidet P-40, $10 \%$ glycerol, and $1 \mathrm{~mm}$ phenylmethylsulfonyl fluoride) for $1.5 \mathrm{~h}$ at $4{ }^{\circ} \mathrm{C}$ at $48 \mathrm{~h}$ after transfection. The cell extracts were cleared, and the supernatant was incubated at $4{ }^{\circ} \mathrm{C}$ with anti-HA $(1 \mu \mathrm{g}$; Roche Molecular Biochemicals), anti-FLAG $(1 \mu \mathrm{g}$, Santa Cruz Biotechnology), or anti- $\beta$-arr2 (1:1000) antibody for $2 \mathrm{~h}$. Immune complexes were immobilized on protein A (Amersham Biosciences, Needham, MA) or anti-chicken IgY Sepharose beads (Promega) for $3 \mathrm{~h}$, washed three times with lysis buffer, and heated in SDS sample buffer in a $50{ }^{\circ} \mathrm{C}$ water bath for $20 \mathrm{~min}$. Western blot analysis was performed as previously described. ${ }^{28} \mathrm{HA}$-tagged proteins were detected with an antiHA antibody, and FLAG-tagged proteins were detected with an antiFLAG antibody. Endogenous eIF2 $\alpha$ was detected with an antibody specific to eIF2 $\alpha$ (Cell Signaling Technology).

Antibodies used for other western blotting included those for $\beta$-arr2, PUMA (Abcam), GRP78 (Enzo life sciences), eIF2 $\alpha$, p-eIF2 $\alpha$, ERp72, cleaved caspase-12, cleaved caspase-4, cleaved caspase-3, caspase- 9 , Cox IV (all from Cell Signaling Technology), sXBP1 (Novus Biologicals, Littleton, CO), Bax, Bak (Abcam), cytochrome c (Santa Cruz), and $\beta$-actin (Sigma-Aldrich). Appropriate horseradish peroxidase-conjugated secondary antibodies were used to detect the primary antibody/antigen complexes. The signal was detected by the ECL system. After quantifying the signals by densitometry, the results were normalized to the signals of the loading controls.

Statistical analysis. All data are expressed as the mean \pm s.d. To compare multiple groups, a two-way analysis of variance was used, followed by Bonferroni's posttest. The differences in values between two groups were determined using Student's $t$-test. A difference was considered statistically significant when $P<0.05$.

SUPPLEMENTARY MATERIAL is linked to the online version of the paper at http://www.nature.com/mi

\section{ACKNOWLEDGMENTS}

We are grateful to Professor Robert $\mathrm{J}$ Lefkowitz at Duke University for providing the $\beta$-arr2 KO mice and the $\beta$-arr2 antibody, Professor Pei G at the Institute of Biochemistry and Cell Biology, Shanghai Institutes for Biological Sciences, Chinese Academy of Sciences for providing the $\beta$-arr2 plasmids, and our doctors and research nurses for their help with collecting the tissue samples. This work was supported partly by grants from the Major Projects Incubator Program of the National Key Basic Research Program of China (2012CB526700), the National Natural Science Foundation of China (81370511), the Natural Science Foundation of Guangdong Province (S2011020002348), the International Cooperative Innovative Platform of Guangdong Province Universities and Colleges (gjhz1101), and the Projects of Guangzhou City International Cooperation (2012J5100017)

\section{DISCLOSURE}

The authors declared no conflict of interest.

c 2015 Society for Mucosal Immunology

\section{REFERENCES}

1. Podolsky, D.K. Inflammatory bowel disease. N. Eng. J. Med. 347, 417-429 (2002).

2. Wolf, D.C. IBD highlights from the 1999 American College of Gastroenterology meeting infiliximab and 6-MP. Inflamm. Bowel Dis. 1, 59-60 (2000).

3. Whalen, E.J., Rajagopal, S. \& Lefkowitz, R.J. Therapeutic potential of betaarrestin and G protein-biased agonists. Trends Mol. Med. 17, 126-139 (2011).

4. Lee, T., Lee, E., Irwin, R., Lucas, P.C., McCabe, L.R. \& Parameswaran, N. Beta-arrestin-1 deficiency protects mice from experimental colitis. Am. J. Pathol. 182, 1114-1123 (2013).
5. Liu, Y. et al. Beta-arrestin2 stimulates interleukin-17 production and expression of CD4 + T lymphocytes in a murine asthma model. Iran J. Allergy Asthma Immunol. 10, 171-182 (2011).

6. Fan, H. et al. Beta-arrestin2 negatively regulates sepsis-induced inflammation. Immunology 130, 344-351 (2010).

7. Li, P. et al. Increased expression of beta-arrestin 1 and 2 in murine models of rheumatoid arthritis: isoform specific regulation of inflammation. Mol. Immunol. 49, 64-74 (2011).

8. Nichols, H.L. et al. Beta-arrestin-2 mediates the proinflammatory effects of proteinase-activated receptor-2 in the airway. Proc. Natl. Acad. Sci. USA 109, 16660-16665 (2012).

9. Thathiah, A. et al. $\beta$-arrestin 2 regulates $A \beta$ generation and $\gamma$-secretase activity in Alzheimer's disease. Nat. Med. 19, 43-49 (2012).

10. Qiu, W. et al. PUMA-mediated intestinal epithelial apoptosis contributes to ulcerative colitis in humans and mice. J. Clin. Invest. 121, 1722-1732 (2011).

11. Ghosh, A.P., Klocke, B.J., Ballestas, M.E. \& Roth, K.A. CHOP potentially co-operates with FOXO3a in neuronal cells to regulate PUMA and BIM expression in response to ER stress. PLoS One 7, e39586 (2012).

12. Kaser, A. et al. XBP1 links ER stress to intestinal inflammation and confers genetic risk for human inflammatory bowel disease. Cell 134, 743-756 (2008).

13. Kieran, D., Woods, I., Villunger, A., Strasser, A. \& Prehn, J.H. Deletion of the BH3-only protein puma protects motoneurons from ER stress-induced apoptosis and delays motoneuron loss in ALS mice. Proc. Natl. Acad. Sc.i USA 104, 20606-20611 (2007).

14. Xu, C., Bailly-Maitre, B. \& Reed, J.C. Endoplasmic reticulum stress: cell life and death decisions. J. Clin. Invest. 115, 2656-2664 (2005).

15. Zhang, K. \& Kaufman, R.J. The unfolded protein response: a stress signaling pathway critical for health and disease. Neurology 66 (Suppl), S102-S109 (2006).

16. Zhang, K. \& Kaufman, R.J. From endoplasmic-reticulum stress to the inflammatory response. Nature 454, 455-462 (2008).

17. Kaser, A. \& Blumberg, R.S. Endoplasmic reticulum stress and intestinal inflammation. Mucosal Immunol. 3, 11-16 (2010).

18. Harding, H.P. et al. An integrated stress response regulates amino acid metabolism and resistance to oxidative stress. Mol. Cell 11, 619-633 (2003).

19. Cooper, H.S., Murthy, S.N., Shah, R.S. \& Sedergran, D.J. Clinicopathologic study of dextran sulfate sodium experimental murine colitis. Lab. Invest. 69, 238-249 (1993).

20. Siegmund, B., Lehr, H.A., Fantuzzi, G. \& Dinarello, C.A. IL-1 betaconverting enzyme (caspase-1) in intestinal inflammation. Proc. Natl. Acad. Sci. USA 98, 13249-13254 (2001).

21. Yin, X.M. et al. Bid-deficient mice are resistant to Fas-induced hepatocellular apoptosis. Nature 400, 886-891 (1999).

22. Edelblum, K.L., Yan, F., Yamaoka, T. \& Polk, D.B. Regulation of apoptosis during homeostasis and disease in the intestinal epithelium. Inflamm. Bowel Dis. 12, 413-424 (2006).

23. Li, Z. et al. Reciprocal changes of Foxp3 expression in blood and intestinal mucosa in IBD patients responding to infliximab. Inflamm. Bowel Dis. 16, 1299-1310 (2010).

24. Heddie, L.N. et al. $\beta$-Arrestin-2 mediates the proinflammatory effects of proteinase-activated receptor-2 in the airway. Proc. Natl. Acad. Sci. USA 109, 16660-16665 (2012).

25. Wang, X., Olberding, K.E., White, C. \& Li, C. Bcl-2 proteins regulate ER membrane permeability to luminal proteins during ER stress-induced apoptosis. Cell Death Differ. 18, 38-47 (2011).

26. Han, C., Nam, M.K., Park, H.J., Seong, Y.M., Kang, S. \& Rhim, H. Tunicamycin-induced ER stress upregulates the expression of mitochondrial HtrA2 and promotes apoptosis through the cytosolic release of HtrA2. J. Microbiol. Biotechnol. 18, 1197-1202 (2008).

27. Luttrell, L.M. et al. Beta-arrestin-dependent formation of beta2 adrenergic receptor-Src protein kinase complexes. Science 283, 655-661 (1999).

28. Wu, B. et al. p53 independent induction of PUMA mediates intestinal apoptosis in response to ischaemia-reperfusion. Gut 56, 645-654 (2007).

29. Xavier, R.J. \& Podolsky, D.K. Unravelling the pathogenesis of inflammatory bowel disease. Nature 448, 427-434 (2007).

30. Zhao, L. \& Ackerman, S.L. Endoplasmic reticulum stress in health and disease. Curr. Opin. Cell Biol. 18, 444-452 (2006). 
31. McGuckin, M.A., Eri, R.D., Das, I., Lourie, R. \& Florin, T.H. ERstress and the unfolded protein response in intestinal inflammation. Am. J. Physiol. Gastrointest. Liver Physiol. 298, G820-G832 (2008).

32. Heazlewood, C.K. et al. Aberrant mucin assembly in mice causes endoplasmic reticulum stress and spontaneous inflammation resembling ulcerative colitis. PLoS Med. 5, e54 (2008).

33. Shkoda, A. et al. Interleukin-10 blocked endoplasmic reticulum stress in intestinal epithelial cells: impact on chronic inflammation. Gastroenterology 132, 190-207 (2007).

34. Bertolotti, A. et al. Increased sensitivity to dextran sodium sulfate colitis in IRE1beta-deficient mice. J. Clin. Invest. 107, 585-593 (2001).

35. Nickson, P., Toth, A. \& Erhardt, P. PUMA is critical for neonatal cardiomyocyte apoptosis induced by endoplasmic reticulum stress. Cardiovasc. Res. 73, 48-56 (2007).

36. Sorokina, O. \& Goryanin, I. European Journal of Pharmaceutical Sciences. Preface. Eur. J. Pharm. Sci. 46, 189 (2012).
37. Galehdar, Z., Swan, P., Fuerth, B., Callaghan, S.M., Park, D.S. \& Cregan, S.P. Neuronal apoptosis induced by endoplasmic reticulum stress is regulated by ATF4-CHOP-mediated induction of the Bcl-2 homology 3only member PUMA. J. Neurosci. 30, 16938-16948 (2010).

38. Yu, J. \& Zhang, L. PUMA, a potent killer with or without p53. Oncogene 27 (Suppl), S71-S83 (2008).

39. Han, J. et al. Expression of bbc3, a pro-apoptotic BH3-only gene, is regulated by diverse cell death and survival signals. Proc. Natl. Acad. Sci. USA 98, 11318-11323 (2001).

40. Luan, B., Zhang, Z., Wu, Y., Kang, J. \& Pei, G. $\beta$-arrestin2 functions as a phosphorylation-regulated suppressor of UV-induced NF- $\mathrm{kB}$ activation. EMBO J. 24, 4237-4246 (2005).

41. Han, X.B., Liu, X., Hsueh, W. \& De Plaen, I.G. Macrophage inflammatory protein-2 mediates the bowel injury induced by platelet-activating factor. Am. J. Physiol. Gastrointest. Liver Physiol. 287, G1220-G1226 (2004).

42. Becker, C., Fantini, M.C. \& Neurath, M.F. High resolution colonoscopy in live mice. Nat. Protoc. 1, 2900-2904 (2006). 